\title{
The antibiotic resistance of Helicobacter pylori to five antibiotics and influencing factors in an area of China with a high risk of gastric cancer
}

\author{
Dan Wang ${ }^{1,2,3}$, Qianqian Guo $0^{1,2,3}$, Yuan Yuan ${ }^{1,2,3^{*}}$ and Yuehua Gong ${ }^{1,2,3^{*}}$ (D)
}

\begin{abstract}
Background: H. pylori exhibits antibiotic resistance with regional differences. In this paper, we explored antibiotic resistance of $\mathrm{H}$. pylori to five antibiotics in an area with a high risk of gastric cancer.

Results: H. pylori resistance rates to metronidazole, levofloxacin, clarithromycin, amoxicillin, and tetracycline were 78.0, 56.0, 31.0, 9.0, and 15.0\%, respectively. Double, triple, quadruple, and quintuple resistance rates were 23, 20, 6 , and $4 \%$, respectively. The clarithromycin and multidrug resistance rates were significantly higher in males than females (clarithromycin: $44.4 \%$ vs $15.2 \%$, respectively, $P=0.002$; multidrug: $75.5 \%$ vs $37.2 \%$, respectively; $P<0.001$ ). During the three periods of 1998-1999, 2002-2004 and 2016-2017, the resistance rates to levofloxacin and amoxicillin were increasing (OR: 2.089, 95\%Cl: 1.142-3.821, $P=0.017$; and OR: 5.035, 95\%Cl: 1.327-19.105, $P=0.018$, respectively). The antibiotic resistance rates were unassociated with the host disease state. Metronidazole resistance was lower in the vacAs $1 \mathrm{~m} 1 / \mathrm{m} 2$ group than the vacAs $1 \mathrm{~m} 1 \mathrm{~m} 2$ group ( $65 \%$ vs $85.7 \%$, respectively; $P=0.026)$. As for levofloxacin resistance, it was higher with cagA ${ }^{+}$than $\operatorname{cag}^{-}(60.9 \%$ vs $23.1 \%$, respectively; $P=0.020)$ but lower with sly $D^{+}$than $s / y D^{-}(41.4 \%$ vs $68.5 \%$, respectively; $P=0.009)$. Clarithromycin had a lower resistance rate with ice $A^{++}$than ice $A^{-+}(19.7 \%$ vs $52.4 \%$, respectively; $P=0.017)$. For amoxicillin, the ice $A^{++}$group had a lower resistance rate than the ice $A^{--}$group $(1.6 \%$ vs $27.8 \%$, respectively; $P=0.009)$.

Conclusions: The total resistance rates of $\mathrm{H}$. pylori to metronidazole, levofloxacin, clarithromycin, amoxicillin, and tetracycline were high in Zhuanghe. The resistanc rates to levofloxacin and amoxicillin increased over time. Clarithromycin resistance was associated with male and iceA. The resistance of metronidazole was related to vacA. Levofloxacin resistance was concerned with cagA and slyD and amoxicillin resistance was concerned with iceA. While, the antibiotic resistance of $\mathrm{H}$. pylori had nothing to do with the status of gastric disease.
\end{abstract}

Keywords: H. pylori, Antibiotic resistance, Virulence factors, High-risk area of gastric cancer

\section{Background}

A number of large randomized controlled trials have shown that the eradication of Helicobacter pylori (H.pylori) can reduce the occurrence of chronic atrophic gastritis and intestinal metaplasia [1] and decrease the risk of gastric cancer [2]. Therefore, the successful eradication of H. pylori is of great significance for the prevention and treatment of

\footnotetext{
* Correspondence: yuanyuan@cmu.edu.cn; yhgong@cmu.edu.cn

${ }^{1}$ Tumor Etiology and Screening Department of Cancer Institute and General Surger, the First Hospital of China Medical University, Shenyang 110001, China

Full list of author information is available at the end of the article
}

gastric diseases. The antibiotics that are commonly used for H. pylori eradication include clarithromycin, metronidazole, amoxicillin, and levofloxacin. In the past few decades, the resistance rate has continued to increase.

The antibiotic resistance of $H$. pylori exhibits regional differences. In Germany [3] and Brazil [4], the antibiotic resistance rate to clarithromycin was 28.7 and $23.2 \%$, respectively, and it was only $7.3 \%$ in Ireland [5] and 0\% in Malaysia [6]. The resistance rate to levofloxacin was $32.7 \%$ in Buenos Aires [7] and 18.2\% in the BogotaColombia [8], as well as $5.8 \%$ in the Hebei Province of

(c) The Author(s). 2019 Open Access This article is distributed under the terms of the Creative Commons Attribution 4.0 International License (http://creativecommons.org/licenses/by/4.0/), which permits unrestricted use, distribution, and 
China [9]. As reported in the literature, the resistance rate to amoxicillin and tetracycline is generally low $[7,10,11]$, but in Ireland and Vietnam, it was as high as $38.1 \%$ [5] and $23.8 \%$ [12], respectively.

There are many factors influencing the antibiotic resistance of $H$. pylori, including age and gender, as well as the host disease status and virulence factors carried by the pathogens. However, there is no consistent report on whether these factors are related to the antibiotic resistance of $H$. pylori. It is well known that the virulence factors secreted by $H$. pylori are closely related to different clinical outcomes in gastric diseases. Cytotoxinassociated gene A (cagA) is the most common virulence factor of $H$. pylori. Some studies have shown that the clarithromycin resistance rate is higher in patients with $\operatorname{cag} A^{+}$than those with $\operatorname{cag} A^{-}$[13], but others have demonstrated that the eradication rate in patients with $\operatorname{cagA} A^{+}$was significantly higher than those with $\operatorname{cag} A^{-}$ [14]. These studies showed that the influencing factors of $H$. pylori antibiotic resistance are different. Therefore, it is necessary to carry out further investigations in different areas.

Zhuanghe, Liaoning Province, a high-risk area for gastric cancer, is in northern China. The H. pylori infection rate for the local residents was more than $60 \%$, and the risk of gastric cancer and precancerous diseases was increased for H. pylori-infected individuals [15]. In this study, we investigated the antibiotic resistance of $H$. pylori to metronidazole, levofloxacin, clarithromycin, amoxicillin, and tetracycline, aimed to provide guidance for the selection of medication, to improve the eradication effect, and to reduce the occurrence of gastric disease.

\section{Methods}

\section{Patients}

A total of 100 strains were collected from the primary cultures of 454 gastric mucosal tissues obtained during an endoscopic biopsy that were all from the Zhuanghe Gastric Diseases Screening Program, started in 1997 [15]. The gastric mucosal tissues were cultured for H.pylori during the 3 periods of 1998-1999, 2002-2004, 2016-2017 were 102, 242 and 110 cases. The number of primary cultured strains was 23,50 , and 27 , respectively, so the total number of specimens in the 3 years was 100 strains. The patients were 54 males and 46 females, ranging from 24 to 87 years old (mean age: $50.74 \pm 10.942$ years). Pathological diagnosis was based on the updated Sydney Classification System, including 21 cases of superficial gastritis (GS), 35 cases of atrophic gastritis (GA), 32 cases of gastric erosion ulcer (GEU), 7 cases of atypical dysplasia (GD), and 5 cases of gastric cancer (GC). Patients were excluded if they had stomach surgery and if they were administered eradication treatment. The study was approved by the Ethics Committee of Chinese Medical University and all participants signed an informed consent.

\section{Antibiotic susceptibility testing}

The susceptibility of $H$. pylori to metronidazole, levofloxacin, clarithromycin, amoxicillin, and tetracycline was tested using an Epsilometer test (E-test, bioMerieux, France). The methods of H.pylori culture and antibiotic susceptibility testing are all the same in different periods. The H. pylori that was in a logarithmic growth period was adjusted to a McFarland standard of 2.0 and smeared evenly with a sterile cotton swab (bioMerieux, France) on Mueller-Hinton agar (Oxoid, Basingstoke, UK), supplemented with 7\% defibrinated sheep blood. The concentration range of the E-test strips was $0.016-256 \mu \mathrm{g} / \mathrm{ml}$ for metronidazole, amoxicillin, and tetracycline (bioMerieux, France); $0.016-256 \mu \mathrm{g} / \mathrm{ml}$ for clarithromycin; and 0.016$32 \mu \mathrm{g} / \mathrm{ml}$ for levofloxacin (Kangtai, China). Then, the plates were incubated at $37^{\circ} \mathrm{C}$ for $48-72 \mathrm{~h}$ in a microaerophilic atmosphere with $10 \% \mathrm{O}_{2}, 5 \% \mathrm{CO}_{2}$, and $85 \% \mathrm{~N}_{2}$. Thereafter, the minimum inhibitory concentration (MIC) for each antibiotic was determined after $48-72 \mathrm{~h}$ by two people independently. The MIC breakpoints were identified using the recommended Clinical and Laboratory Standards Institute (http://www.clsi.org/) of America. Strains were considered resistant with an MIC of $\geq 1 \mathrm{mg} /$ $\mathrm{ml}$ for clarithromycin [16], levofloxacin [17], amoxicillin and tetracycline [18] and $\geq 8 \mathrm{mg} / \mathrm{ml}$ for metronidazole [4]. The H. pylori reference strain, ATCC 26695, was used for quality control.

\section{DNA extraction}

Whole genomic DNA of $H$. pylori was extracted using a phenol-chloroform method [15]. In brief, $300 \mu \mathrm{l}$ of TE buffer $(10 \mathrm{Mm}$ Tris- $\mathrm{HCl}$ [pH 8.3], $0.1 \mathrm{mmol} / \mathrm{l}$ EDTA), $100 \mu \mathrm{l}$ of $10 \%$ SDS, and $10 \mu \mathrm{l}$ of PK enzyme $(20 \mathrm{mg} / \mathrm{ml})$ were added to the bacterial precipitate and digested overnight in a water bath at $55^{\circ} \mathrm{C}$. The extracted DNA was dissolved in $50-100 \mu \mathrm{l}$ of TE buffer and stored at $20^{\circ} \mathrm{C}$.

\section{Polymerase chain reaction amplification of $H$. pylori virulence genes}

H. pylori virulence factors $c a g A, v a c A(\mathrm{~s} 1, \mathrm{~s} 2, \mathrm{~m} 1 \mathrm{a}, \mathrm{m} 1 \mathrm{~b}$, $\mathrm{m} 2$, i1, and i2), iceA1, iceA2, babA2, oipA, slyD, hrgA, and cagA-EPIYA motif were amplified using polymerase chain reaction (PCR) [19-26]. The 25- $\mu$ l amplification system included $2 \mathrm{mmol} / \mathrm{L}$ dNTP, $2.5 \mathrm{U}$ Taq DNA polymerase, $10 \times$ buffer (Takara, China), 10 pmol primer, and $1 \mu \mathrm{l}$ of DNA template. The amplified products were identified using $2 \%$ agarose gel electrophoresis. Both positive and negative controls were performed in parallel for each PCR reaction. 


\section{Statistical analysis}

All statistical analysis was carried out using SPSS V.18.0 software for Windows (SPSS Inc., Chicago, IL, USA). A binary logistic regression model was used to calculate the odds ratios (OR) and 95\% confidence interval $(\mathrm{CI})$. A $P$ value of $<0.05$ was defined as significant.

\section{Results}

\section{The characteristics of $H$. pylori antibiotic resistance}

First, we detected the drug resistance of $100 \mathrm{H}$. pylori strains to the five previously mentioned antibiotics using E-test. The results showed that the total resistance rates of $H$. pylori to metronidazole, levofloxacin, clarithromycin, amoxicillin, and tetracycline were $78.0 \%$ (78/100), 56.0\% (56/100), 31.0\% (31/100), $9.0 \%$ $(9 / 100)$, and $15.0 \%(15 / 100)$, respectively (Figs. 1 and 2). Further analysis revealed that $H$. pylori resistance occurred at high MIC levels. In the metronidazoleresistant strains, $89.7 \%(70 / 78)$ of the MIC values were more than $64 \mu \mathrm{g} / \mathrm{ml}$ and $83.3 \%$ (65/78) exceeded $256 \mu \mathrm{g} / \mathrm{ml}$ (Fig. 1a). In the levofloxacin-resistant strains, 51.8\% (29/56) of the MIC values were $32 \mu \mathrm{g} /$ $\mathrm{ml}$ (Fig. 1b). Among the strains resistant to clarithromycin, $80.6 \%(25 / 31)$ of the MIC values were above $256 \mu \mathrm{g} / \mathrm{ml}$ (Fig. 2a). If stratified by gender and age, we found that the clarithromycin resistance rate was significantly higher for males than females $(44.4 \%$ vs 15.2\%, respectively; OR: 4.457, 95\%CI: 1.694-11.724; $P=0.002)$. There was no significant difference for the resistance rates of the four other antibiotics by gender. Further, no significant difference was demonstrated in the resistance rates for the five antibiotics by age (Table 1 ).

In addition, among the 100 strains of H. pylori, 39 (39\%) had single-drug resistance, 23 (23\%) had double-drug resistance, and 20 (20\%) had triple-drug resistance; meanwhile, $6(6 \%)$ were resistant to four drugs, and $4(4 \%)$ were resistant to all five antibiotics (Table 2). Only 8 (8\%) strains were found to be sensitive to all five antibiotics. As for the multidrugresistant strains, most were double or triple resistant. The highest proportion of a double-drug resistant pattern was metronidazole plus levofloxacin, accounting for $73.9 \%$. The highest proportion of a triple-drug resistance pattern was the combination of metronidazole, levofloxacin, and clarithromycin, accounting for $55 \%$. Similarly, after stratifying by gender and age, the results showed that the multidrug resistance rate was higher for males than females $(75.5 \%$ vs $37.2 \%$, respectively; OR: $5.203,95 \%$ CI: $2.120-12.771, P<0.001$, Table 1). However, there was no significant difference between the single and multidrug resistance rates based on age.
The changing profile of $H$. pylori antibiotic resistance during the past three decades

In this study, we compared the changing profile of $H$. pylori resistance in the Zhuanghe area during three decades from 1998 to 2017 (Fig. 3). During the three periods, 1998-1999, 2002-2004 and 2016-2017, the resistance rate to certain antibiotics was as follows: metronidazole was $87.0,66.0$ and $92.6 \%$, respectively; levofloxacin was $47.8,46.0$ and $81.5 \%$, respectively; clarithromycin was $39.1,14.0$ and $55.6 \%$, respectively; amoxicillin was 4.3, 2.0 and $25.9 \%$, respectively; and tetracycline was $13.0,14.0$ and $18.5 \%$, respectively. Adjusting for age and gender, we found that the resistance rates to metronidazole, clarithromycin, and tetracycline were not significant over the three decades (Table 1), but the resistant rates to levofloxacin and amoxicillin increased (OR: 2.089, 95\%CI: 1.142-3.821, $P=0.017$, respectively; OR: $5.035,95 \% \mathrm{CI}: 1.327-19.105$, $P=0.018$, respectively). In addition, we analyzed the changing profile for the single-drug or multidrug resistance rates over the three decades (Table 1) that showed that the rate of single-drug resistance decreased (OR: 0.411, 95\%CI: $0.205-0.824, P=0.012)$, but the multidrug resistance increased (OR: 2.059, 95\%CI: 1.090-3.889, $P=$ $0.026)$.

The antibiotic resistance of $H$. pylori and host disease state Concerning the relationship between $H$. pylori antibiotic resistance and host disease status, we found that after adjusting for age and gender, there was no significant difference in the antibiotic resistance for the GS, GA, and GEU groups or the GEU and non-gastric erosion ulcer (NGEU) groups (Table 1).

The antibiotic resistance of $H$. pylori and virulence factor The virulence factors $\operatorname{cagA}, \operatorname{vacA}(\mathrm{s} 1, \mathrm{~m} 1, \mathrm{~m} 2$, and 1 ), iceA1, ice $A 2, \operatorname{babA2}$, oipA, slyD, and $h r g A$ and their correlations with the five types of antibiotic resistance were calculated by a binary logistic regression analysis (Table 1). The results showed that the resistance rate to metronidazole was lower in the vacAs $1 \mathrm{~m} 1 / \mathrm{m} 2$ group than the vacAs $1 \mathrm{~m} 1 \mathrm{~m} 2$ group ( $65 \%$ vs $85.7 \%$, respectively; OR: $0.287,95 \% \mathrm{CI}: 0.096-0.863, P=0.026$ ) after adjusting for age and gender. As for the resistance rate to levofloxacin, it was higher in the $\operatorname{cag} A{ }^{+}$ group than the cag $A^{-}$group $(60.9 \%$ vs $23.1 \%$, respectively; OR: $5.133,95 \% \mathrm{CI}: 1.297-20.319, P=0.020)$ but was lower in the $\operatorname{slyD^{+}}$ group than the $\operatorname{sly} D^{-}$group $(41.4 \%$ vs $68.5 \%$, respectively; OR: $0.334,95 \%$ CI: $0.146-0.764, P=0.009)$. A lower resistance rate to clarithromycin was observed in the ice $A^{++}$group than the $i c e A^{-}+$group $(19.7 \%$ vs $52.4 \%$, respectively; OR: 0.234, 95\%CI: $0.071-0.775, P=0.017)$. As for amoxicillin, the $i c e A^{++}$group had a lower resistance rate 


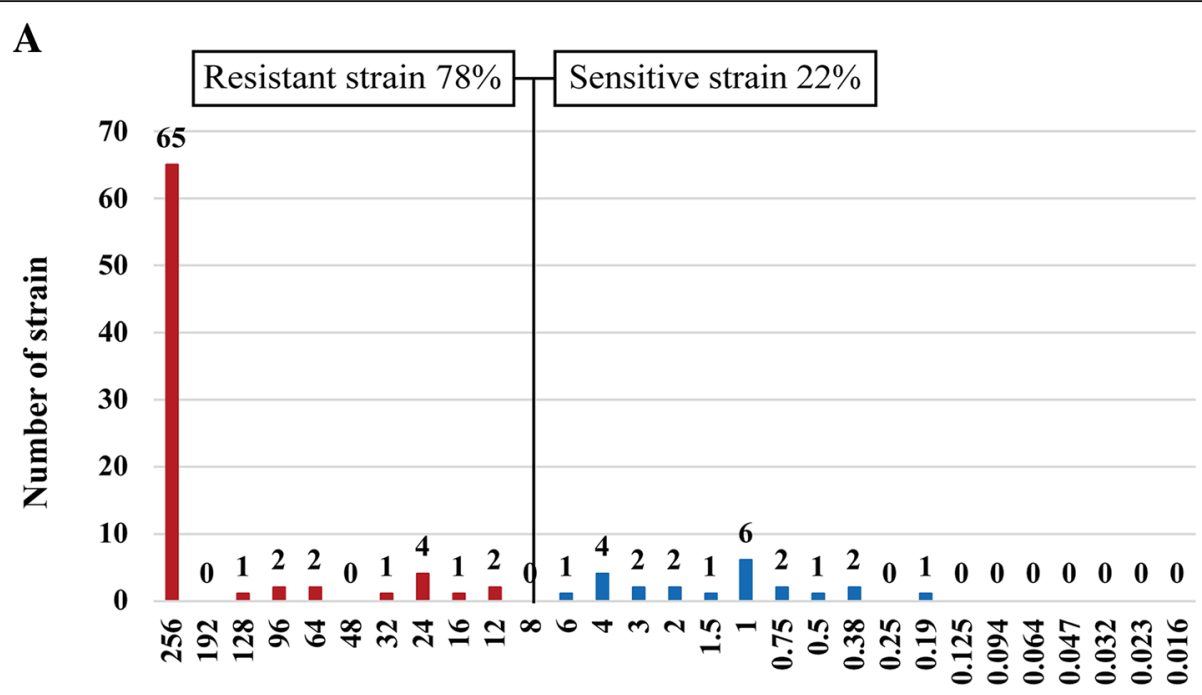

MIC value

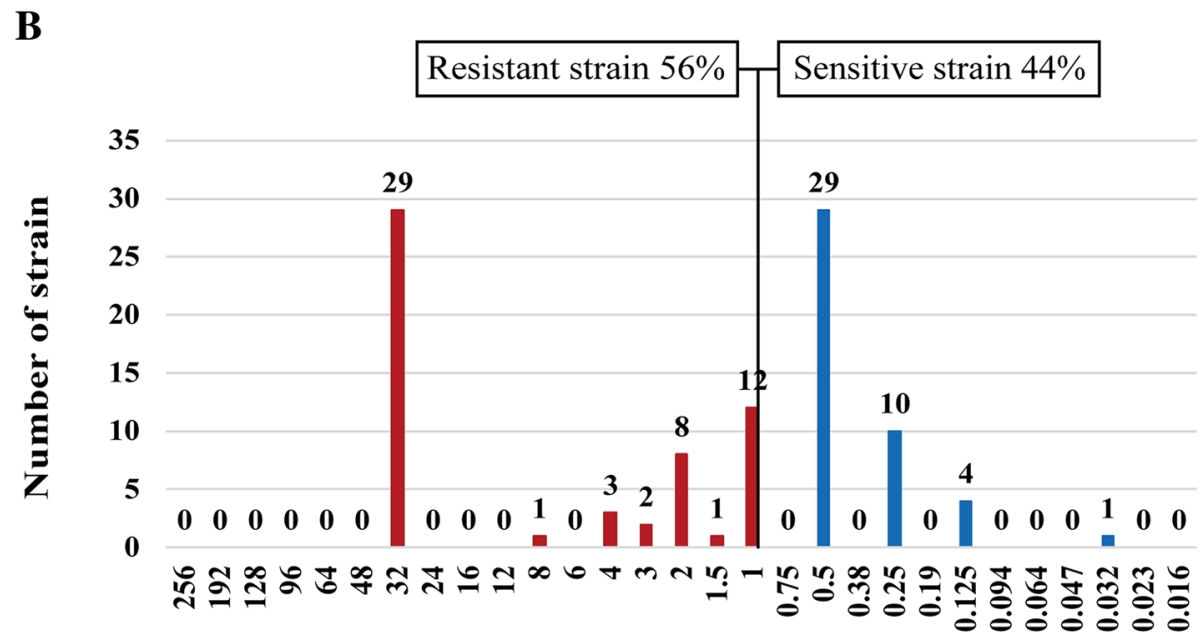

MIC value

Fig. 1 Distribution of the antibiotic (a for metronidazole, b forlevofloxacin), MIC values for the H. pylori isolates in Zhuanghe

than the ice $A^{--}$group $(1.6 \%$ vs $27.8 \%$, respectively; OR: $0.051,95 \% \mathrm{CI}: 0.005-0.481, P=0.009)$. There was no significant difference in the relationship between the other $H$. pylori virulence factors such as vacA, babA, oipA, and $h r g A$ and antibiotic resistance $(P>0.05)$. In addition, to detect the EPIYA motif classifications for the $c a g A^{+}$ ( $n=87$ ) group, we found that it was mainly composed of East Asian type EPIYA-ABD $(n=79)$, western type EPIYA-ABC $(n=2)$, mixed type EPIYA-ABCD $(n=5)$, and one EPIYA-ACD. Because of the small number of cases in the different groups, the statistical relationships for antibiotic resistance cannot be analyzed.

\section{Discussions}

Antibiotic resistance is the main reason for failure to eradicate an $H$. pylori infection. In this study, $100 \mathrm{H}$. pylori strains from Zhuanghe, an area with a high incidence of $\mathrm{GC}$, were included to investigate the antibiotic resistance, to explore the trend over time, and to analyze the factors affecting antibiotic resistance. This study revealed the antibiotic resistance of $H$. pylori to five antibiotics in an area with a high incidence of GC and provided guidance for the treatment of $H$. pylori.

Our study demonstrated that the total resistance rates of $H$. pylori to metronidazole, levofloxacin, and 


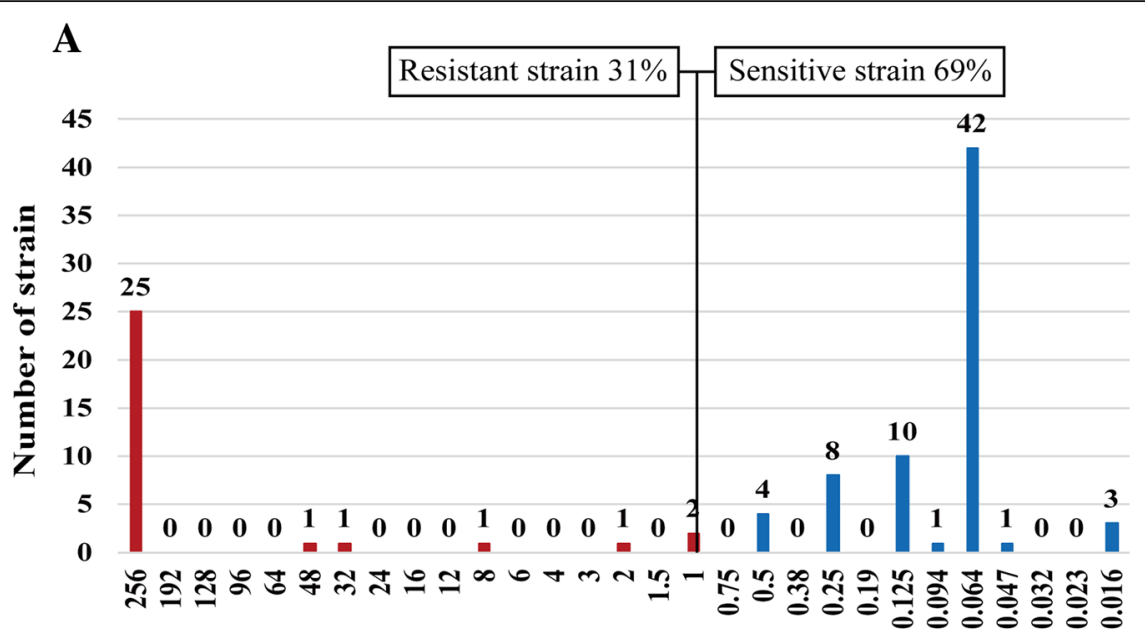

MIC value

B

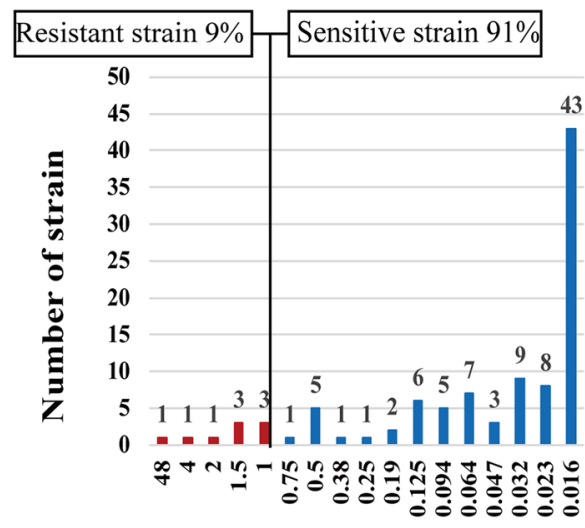

MIC value
C

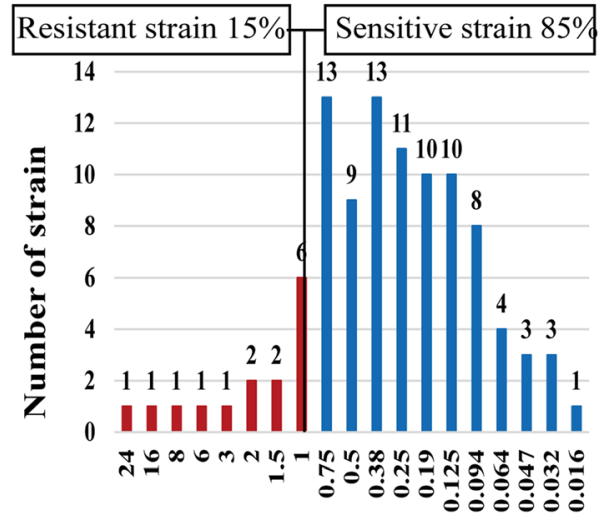

MIC value

Fig. 2 Distribution of the antibiotic (a for clarithromycin, $\mathbf{b}$ for amoxicillin, and $\mathbf{c}$ for tetracycline). MIC values for the H. pylori isolates in Zhuanghe

clarithromycin were 78,56 , and $31 \%$, respectively, with high MIC levels; however, the resistance rates to amoxicillin and tetracycline were low, and the multidrug resistance rate was as high as $53 \%$. As compared with low-risk areas for GC in China [27-29], neighboring countries [30$33]$, and other non-neighboring countries [6, 11, 34, 35], the antibiotic resistance was generally higher in the Zhuanghe area. The high antibiotic resistance increased the risk of $H$. pylori transmission among the population and caused a widespread and persistent high infection rate of $H$. pylori in the population; moreover, it also could increase the continued colonization of the stomach in hosts and increase the inflammation of and damage to the gastric mucosa, which may lead to an increased risk of GC.

According to previous studies, $H$. pylori antibiotic resistance has significantly changed over time [8, 33, 36-38]. For example, in Korea, the resistance rate to clarithromycin increased from 11 to $60 \%$ from 2009 to $2014[39,40]$. In Singapore, the resistance rate to metronidazole increased from 24.8 to $48.2 \%$ from 2000 to 2014 [38]. Our results showed that the resistance rates to clarithromycin and metronidazole maintained a stable yet high level and that tetracycline was at a steady yet low level in 1998-2017. The resistance rates to levofloxacin and amoxicillin, as well as multidrug resistance, have demonstrated an increasing trend. Our study showed that the two antibiotics, clarithromycin and metronidazole, were not suitable for eradication therapy in this area. However, tetracycline can be used to eradicate $H$. pylori but has a shortcoming because of adverse reactions, so the time and dose should be strictly controlled. Developing alternative drugs to help with eradication is also a future goal.

In this study, we found that the resistance rate to clarithromycin for males was significantly higher than 


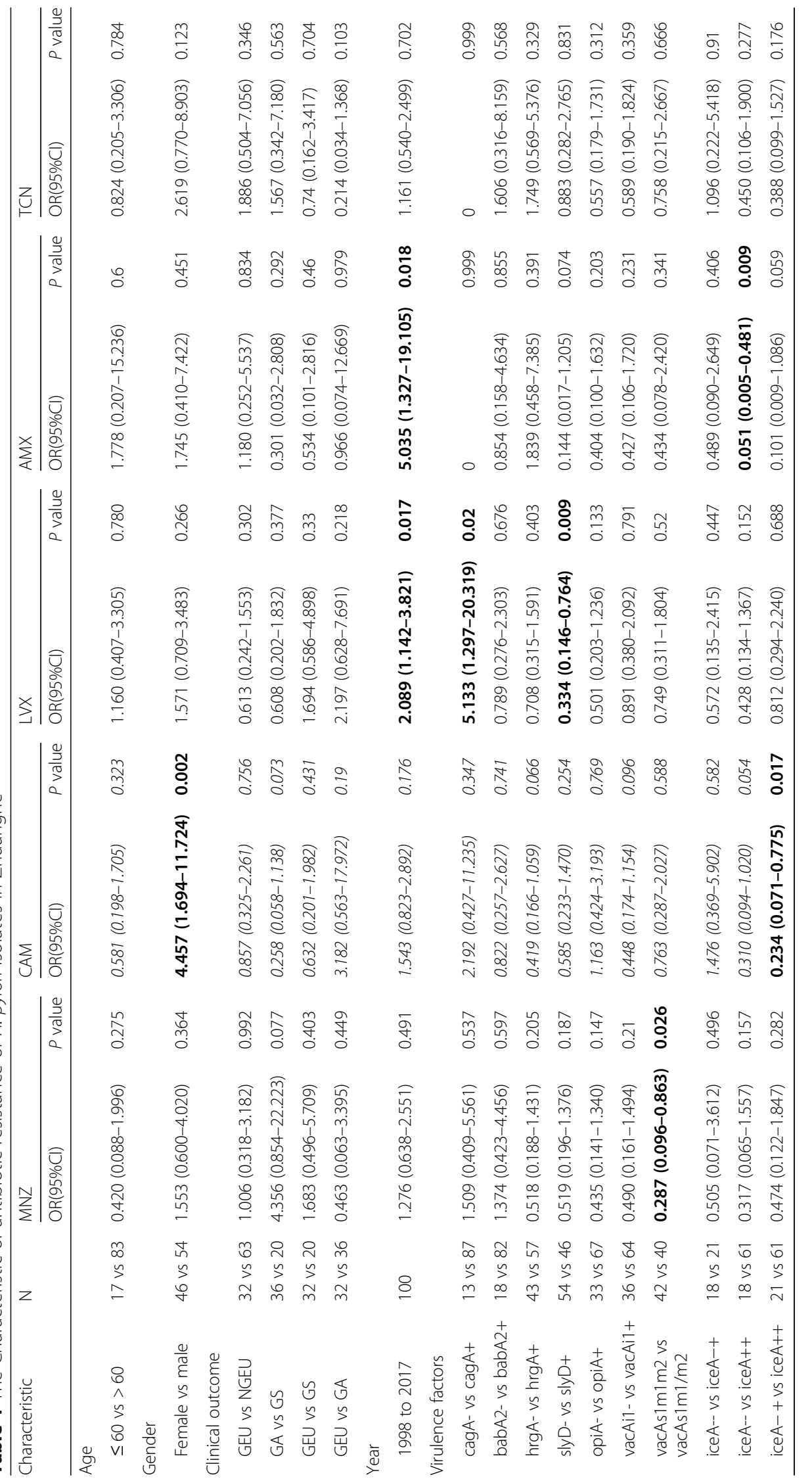


Table 2 Distribution of resistance patterns among H. pylori strains

\begin{tabular}{|c|c|}
\hline Susceptibility test results & $\mathrm{N}$ \\
\hline Sensitive to all $A B s$ & 8 \\
\hline Single & 39 \\
\hline MNZ & 26 \\
\hline LVX & 9 \\
\hline CAM & 3 \\
\hline AMX & 0 \\
\hline TCN & 1 \\
\hline Double & 23 \\
\hline$M N Z+L V X$ & 17 \\
\hline $\mathrm{MNZ}+\mathrm{CAM}$ & 5 \\
\hline$L V X+C A M$ & 1 \\
\hline Triple & 20 \\
\hline$M N Z+L V X+C A M$ & 11 \\
\hline$M N Z+L V X+T C N$ & 6 \\
\hline$M N Z+L V X+A M X$ & 2 \\
\hline$M N Z+C A M+A M X$ & 1 \\
\hline Quadruple & 6 \\
\hline$M N Z+L V X+C A M+A M X$ & 2 \\
\hline$M N Z+L V X+C A M+T C N$ & 4 \\
\hline Resistance to all $\mathrm{ABs}$ & 4 \\
\hline
\end{tabular}

Abbreviations: $A B$ antibiotic

females. Boyanova [41] also had similar conclusions in females and males. In addition, we found males are more prone to multidrug resistance than females. The possible causes of this phenomenon was that macrolide antibiotics were commonly used for the treatment of respiratory diseases and respiratory infections related to smoking and other factors mostly occurred in men that might lead to antibiotic resistance for males with a clarithromycin-based eradication treatment for $H$. pylori. Previous studies of our group showed that the incidence and mortality of males with GC in the Zhuanghe area were higher than those of females by 2.8 times and 2.3 times, respectively [42]. Thus, the high antibiotic resistance of $H$. pylori for males might also be one risk factor for GC in addition to environmental exposure factors such as diet, smoking, drinking, and occupation.

In addition, there have been different reports on whether the gastric disease status is related to the antibiotic resistance of $H$. pylori. A study involving 2751 patients in France showed that the successful eradication rate of $H$. pylori in patients with a duodenal ulcer was higher than that of patients with a non-ulcer-related dyspepsia [43]. However, some medical literature indicated that these diseases are not related to antibiotic resistance $[30,41,44-47]$. In the present study, we found that the $H$. pylori resistance rate was not associated with gastric disease. However, while analyzing the reason, on the one hand, it may be geographical differences. On the other hand, it may be because of the small number of cases included in this study.

Some virulence factors carried by $H$. pylori may also affect the clinical outcomes of eradication [48-50]. As compared with single- and multi-strain infections, we found that the resistance rate of metronidazole to $v a c A \mathrm{~m} 1$ or $v a c A \mathrm{~m} 2$ was lower than that of a mixed infection with $v a c A \mathrm{~m} 1 \mathrm{~m} 2$, to ice $A 1$ or ice $A 2$ alone higher than that of mixed infection with iceA1A2. The resistance rate to amoxicillin in $i c e A^{--}$was higher than that of a mixed infection. Additionally, the resistance rate to levofloxacin was higher in the $\operatorname{cagA}{ }^{+}$group than the $\operatorname{cag} A^{-}$one. The resistance rate to levofloxacin was higher in the $s l y D^{-}$group than the $s l y D^{+}$one. $C a g A^{+}$or mixed $v a c A s 1 \mathrm{~m} 1 \mathrm{~m} 2$ infection was associated with antibiotic resistance. Patients infected with such strains had more difficulty achieving eradication of $H$. pylori, and continuous colonization was more likely to induce precancerous lesions and GC. Therefore, decreasing the incidence of GC could be achieved so long as the emergence of antibiotic resistance is avoided during the administration of effective eradication treatment. In addition, a mixed iceA or sly $D^{+}$strain would be easy to eradicate according to the present study results. However, in some reports both iceA 1 and ice $A 2$ infections were unrelated to the eradication outcomes [51, 52]. $S l y D$ was a new virulence factor associated with gastric disease [53]. To our knowledge, until now, there was no report on the relationship between $s l y D$ and antibiotic resistance. Therefore, the relationship between these two virulence factors and bacterial resistance needs to be further explored.

This study had the following limitations: 1 . Since there exists dominant genotype of H.pylori virulence factors eg. cagA positive, $v a c A \mathrm{~s} 1 \mathrm{~m} 1$, and ice $A 1$ positive in this area [15], therefore, the relationship between virulence factors and antibiotic resistance needs to be further investigated. 2 . The obtained conclusions in the present study were based in a number of only 100 strains, the factors affecting the antibiotic resistance still needs to further verification in a large samples. 3. Other factors such as host CYP2C19, MDR, and IL-1 $\beta$ gene polymorphism can also influence $H$. pylori eradication. However, there is a lack of relevant information in our study, so we could not evaluate it.

\section{Conclusions}

In conclusion, our study evaluated the antibiotic resistance and influencing factors of $H$. pylori in Zhuanghe. The total resistance rates to metronidazole, levofloxacin, clarithromycin, amoxicillin, and tetracycline were high. The resistance rates to levofloxacin and amoxicillin increased over time. Clarithromycin resistance was 


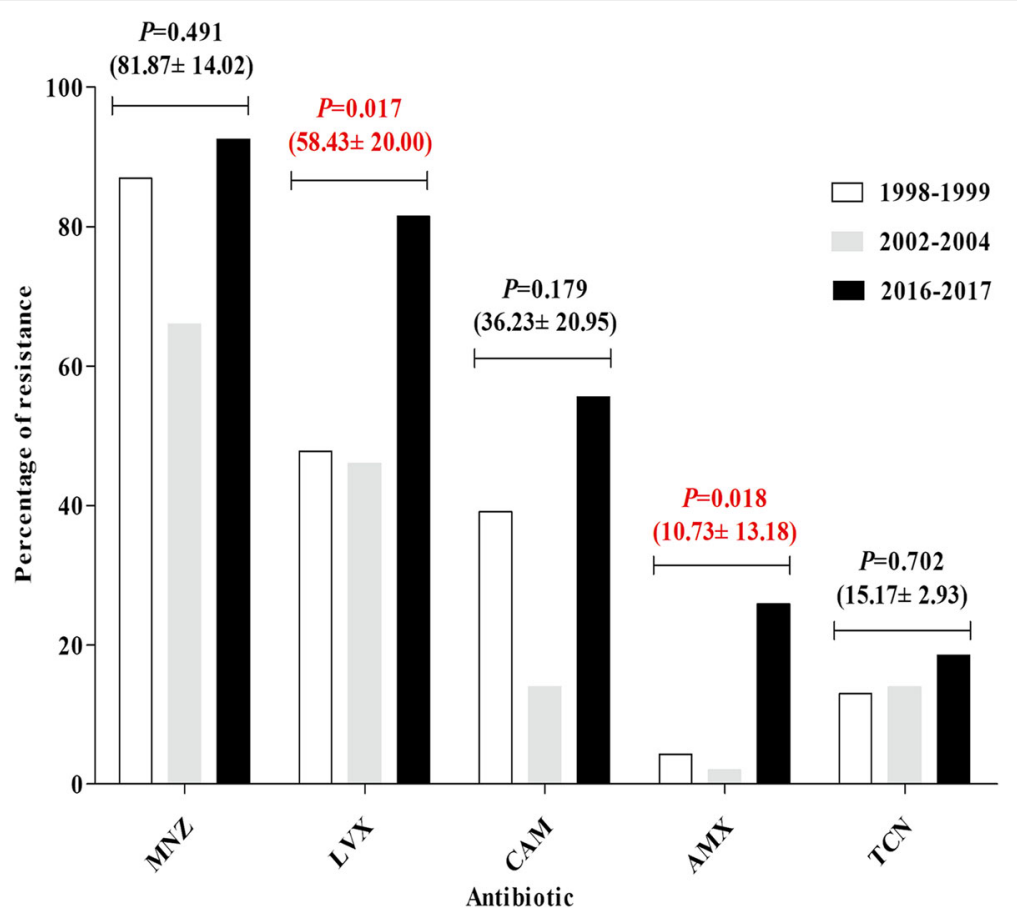

Fig. 3 The changing profile for $H$. pylori antibiotic resistance during the three decades

associated with male and iceA. The resistance of metronidazole was related to $v a c A$. Levofloxacin resistance was concerned with $\operatorname{cag} A$ and $\operatorname{sly} D$ and amoxicillin resistance was concerned with iceA. While, the antibiotic resistance of $H$. pylori had nothing to do with the status of gastric disease. Per this study, clarithromycin-based triple therapy is no longer applicable in this area; metronidazole and levofloxacin should be used with high vigilance; and amoxicillin and tetracycline can be used as candidates for antibiotic treatment. Virulence factors including cagA, vacA, iceA, and $\operatorname{sly} D$ can be used to predict antibiotic resistance. Our study is beneficial to the selection of the $H$. pylori eradication program that is conducive to reducing the infection rate, thus helping in the prevention and treatment of GC and related gastric diseases.

\section{Abbreviations}

AMX: Amoxicillin; CAM: Calrithromycin; GA: Atrophic gastritis; GC: Gastric cancer; GD: Atypical dysplasia; GEU: Gastric erosion ulcer; GS: Superficial gastritis; LVX: Levofloxacin; MIC: Minimum inhibitory concentration; MNZ: Metronidazole; NGEU: Non-gastric erosion ulcer (NGEU); TCN: Tetracycline

\section{Acknowledgements}

Not applicable.

\section{Authors' contributions}

YY and YHG designed the experiment. DW conducted the experiment. DW and YHG analysed the samples and performed data analysis. DW produced the first draft of the manuscript and QQG contributed to drafting and editing the manuscript. All the authors have read and approved the final version of the manuscript.

\section{Funding}

This work was supported by the National Key R\&D Program of China (Grant No.2017YFC0908300) and Natural Science Foundation of Liaoning Province (Grant No. 201602822). The design of this study, sample collections and data analysis were supported by Grant No.2017YFC0908300. The writing of this manuscript was aided by Grant No. 201602822.

Availability of data and materials

All data generated or analysed during this study are included in this published article.

\section{Ethics approval and consent to participate}

The study was approved by the Ethics Committee of Chinese Medical University and all participants signed an informed consent.

\section{Consent for publication}

Not applicable.

\section{Competing interests}

The authors declare that they have no competing interests.

\section{Author details}

${ }^{1}$ Tumor Etiology and Screening Department of Cancer Institute and General Surger, the First Hospital of China Medical University, Shenyang 110001,

China. ${ }^{2}$ Key Laboratory of Cancer Etiology and Prevention in Liaoning Education Department, the First Hospital of China Medical University, Shenyang 110001, China. ${ }^{3}$ Key Laboratory of GI Cancer Etiology and Prevention in Liaoning Province, the First Hospital of China Medical University, Shenyang 110001, China.

Received: 9 May 2018 Accepted: 17 June 2019

Published online: 04 July 2019

\section{References}

1. You WC, Brown LM, Zhang L, Li JY, Jin ML, Chang YS, et al. Randomized double-blind factorial trial of three treatments to reduce the prevalence of precancerous gastric lesions. J Natl Cancer Inst. 2006;98(14):974-83. 
2. Take S, Mizuno M, Ishiki K, Hamada F, Yoshida T, Yokota K, et al. Seventeen-year effects of eradicating helicobacter pylori on the prevention of gastric cancer in patients with peptic ulcer; a prospective cohort study. J Gastroenterol. 2015;50(6):638-44.

3. Regnath $T$, Raecke $O$, Enninger A, Ignatius R. Increasing metronidazole and rifampicin resistance of helicobacter pylori isolates obtained from children and adolescents between 2002 and 2015 in Southwest Germany. Helicobacter. 2017:22(1):e12327.

4. Ogata SK, Godoy AP, da Silva Patricio FR, Kawakami E. High helicobacter pylori resistance to metronidazole and clarithromycin in Brazilian children and adolescents. J Pediatr Gastroenterol Nutr. 2013;56(6):645-8.

5. Siavoshi F, Saniee P, Latifi-Navid S, Massarrat S, Sheykholeslami A. Increase in resistance rates of $\mathrm{H}$. pylori isolates to metronidazole and tetracycline-comparison of three 3-year studies. Arch Iran Med. 2010;13(3):177-87.

6. Goh KL, Navaratnam P. High helicobacter pylori resistance to metronidazole but zero or low resistance to clarithromycin, levofloxacin, and other antibiotics in Malaysia. Helicobacter. 2011;16(3):241-5.

7. Zerbetto De Palma G, Mendiondo N, Wonaga A, Viola L, Ibarra D,

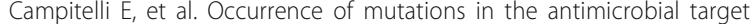
genes related to levofloxacin, clarithromycin, and amoxicillin resistance in helicobacter pylori Isolates from Buenos Aires City. Microb Drug Resist. 2017;23(3):351-8.

8. Trespalacios-Rangel AA, Otero W, Arevalo-Galvis A, Poutou-Pinales RA, Rimbara E, Graham DY. Surveillance of levofloxacin resistance in helicobacter pylori isolates in Bogota-Colombia (2009-2014). PLoS One. 2016;11(7):e0160007.

9. Meng X, Liu G, Wu J, Kong C, Zhao L, Zhu X, et al. Antibiotic resistance of helicobacter pylori clinical isolates in Hebei Province. Zhonghua Yi Xue Za Zhi. 2016;96(4):270-2.

10. Miftahussurur M, Cruz M, Subsomwong P, Jimenez Abreu JA, Hosking C, Nagashima $\mathrm{H}$, et al. Clarithromycin-based triple therapy is still useful as an initial treatment for helicobacter pylori infection in the Dominican Republic. Am J Trop Med Hyg. 2017;96(5):1050-9.

11. Macias-Garcia F, Llovo-Taboada J, Diaz-Lopez M, Baston-Rey I, DominguezMunoz JE. High primary antibiotic resistance of helicobacter pylori strains isolated from dyspeptic patients: a prevalence cross-sectional study in Spain. Helicobacter. 2017;22(6). https://doi.org/10.1111/hel.12440.

12. Quek C, Pham ST, Tran KT, Pham BT, Huynh LV, Luu NB, et al. Antimicrobial susceptibility and clarithromycin resistance patterns of helicobacter pylori clinical isolates in Vietnam. F1000Research. 2016;5:671.

13. Khan A, Farooqui A, Manzoor H, Akhtar SS, Quraishy MS, Kazmi SU. Antibiotic resistance and cagA gene correlation: a looming crisis of helicobacter pylori. World J Gastroenterol. 2012;18(18):2245-52.

14. van der Hulst RW, van der Ende A, Dekker FW, Ten Kate FJ, Weel JF, Keller JJ, et al. Effect of helicobacter pylori eradication on gastritis in relation to cagA: a prospective 1-year follow-up study. Gastroenterology. 1997;113(1):25-30.

15. Gong $Y H$, Wang $Y$, Yuan Y. Distribution of helicobacter pylori in North China. World J Gastroenterol. 2005;11(23):3523-7.

16. Hirata K, Suzuki H, Nishizawa T, Tsugawa H, Muraoka H, Saito Y, et al. Contribution of efflux pumps to clarithromycin resistance in helicobacter pylori. J Gastroenterol Hepatol. 2010;25(Suppl 1):S75-9.

17. Teh X, Khosravi Y, Lee WC, Leow AH, Loke MF, Vadivelu J, et al. Functional and molecular surveillance of helicobacter pylori antibiotic resistance in Kuala Lumpur. PLoS One. 2014;9(7):e101481.

18. Wuppenhorst N, Lenze F, Ross M, Kist M. Isolation and eradication of a clinical isolate of helicobacter pylori resistant to five antimicrobials in Germany. J Antimicrob Chemother. 2011;66(1):222-3.

19. Pan ZJ, van der Hulst RW, Feller M, Xiao SD, Tytgat GN, Dankert J, et al. Equally high prevalences of infection with cagA-positive helicobacter pylori in Chinese patients with peptic ulcer disease and those with chronic gastritis-associated dyspepsia. J Clin Microbiol. 1997;35(6):1344-7.

20. Atherton JC, Cao P, Peek RM Jr, Tummuru MK, Blaser MJ, Cover TL. Mosaicism in vacuolating cytotoxin alleles of helicobacter pylori. Association of specific vacA types with cytotoxin production and peptic ulceration. J Biol Chem. 1995;270(30):17771-7.

21. Li Q, Zhu Y, Liu J, Yu X, Chen M, Dong N, et al. HpSlyD inducing CDX2 and VIL1 expression mediated through TCTP protein may contribute to intestinal metaplasia in the stomach. Sci Rep. 2017;7(1):2278.

22. G M, Tiwari SK, Sharma V, Habeeb MA, Khan AA, Cm H. Association of Helicobacter pylori restriction endonuclease-replacing gene, hrgA with overt gastrointestinal diseases. Arq Gastroenterol. 2008;45(3):225-9.
23. van Doorn LJ, Figueiredo C, Rossau R, Jannes G, van Asbroek M, Sousa JC, et al. Typing of helicobacter pylori vacA gene and detection of cagA gene by PCR and reverse hybridization. J Clin Microbiol. 1998;36(5):1271-6.

24. Arevalo-Galvis A, Trespalacios-Rangell AA, Otero W, Mercado-Reyes MM, Poutou-Pinales RA. Prevalence of cagA, vacA, babA2 and iceA genes in $\mathrm{H}$. pylori strains isolated from Colombian patients with functional dyspepsia. Pol J Microbiol. 2012;61(1):33-40.

25. Versalovic J, Koeuth T, Lupski JR. Distribution of repetitive DNA sequences in eubacteria and application to fingerprinting of bacterial genomes. Nucleic Acids Res. 1991;19(24):6823-31.

26. Schmidt HM, Goh KL, Fock KM, Hilmi I, Dhamodaran S, Forman D, et al. Distinct cagA EPIYA motifs are associated with ethnic diversity in Malaysia and Singapore. Helicobacter. 2009;14(4):256-63.

27. Han R, Lu H, Jiang MW, Tan KW, Peng Z, Hu JL, et al. Multicenter study of antibiotic resistance profile of $\mathrm{H}$. pylori and distribution of CYP2C19 gene polymorphism in rural population of Chongqing, China. Gastroenterol Res Pract. 2016;2016:8547686.

28. Su P, Li Y, Li H, Zhang J, Lin L, Wang Q, et al. Antibiotic resistance of helicobacter pylori isolated in the southeast coastal region of China. Helicobacter. 2013;18(4):274-9.

29. Gao W, Cheng H, Hu F, Li J, Wang L, Yang G, et al. The evolution of helicobacter pylori antibiotics resistance over 10 years in Beijing, China. Helicobacter. 2010;15(5):460-6.

30. Binh TT, Shiota S, Nguyen LT, Ho DD, Hoang HH, Ta L, et al. The incidence of primary antibiotic resistance of helicobacter pylori in Vietnam. J Clin Gastroenterol. 2013;47(3):233-8.

31. Chung JW, Lee GH, Jeong JY, Lee SM, Jung JH, Choi KD, et al. Resistance of helicobacter pylori strains to antibiotics in Korea with a focus on fluoroquinolone resistance. J Gastroenterol Hepatol. 2012;27(3):493-7.

32. Okamura T, Suga T, Nagaya T, Arakura N, Matsumoto T, Nakayama Y, et al. Antimicrobial resistance and characteristics of eradication therapy of helicobacter pylori in Japan: a multi-generational comparison. Helicobacter. 2014;19(3):214-20.

33. Kuo YT, Liou JM, El-Omar EM, Wu JY, Leow AHR, Goh KL, et al. Primary antibiotic resistance in helicobacter pylori in the Asia-Pacific region: a systematic review and meta-analysis. Lancet Gastroenterol Hepatol. 2017; 2(10):707-15.

34. Caliskan R, Tokman HB, Erzin Y, Saribas S, Yuksel P, Bolek BK, et al. Antimicrobial resistance of helicobacter pylori strains to five antibiotics, including levofloxacin, in northwestern Turkey. Rev Soc Bras Med Trop. 2015;48(3):278-84

35. Shiota S, Reddy R, Alsarraj A, El-Serag HB, Graham DY. Antibiotic resistance of helicobacter pylori among male United States veterans. Clin Gastroenterol Hepatol. 2015;13(9):1616-24.

36. De Francesco V, Giorgio F, Hassan C, Manes G, Vannella L, Panella C, et al. Worldwide $\mathrm{H}$. pylori antibiotic resistance: a systematic review. J Gastrointestin Liver Dis. 2010;19(4):409-14.

37. Kostamo P, Veijola L, Oksanen A, Sarna S, Rautelin H. Recent trends in primary antimicrobial resistance of helicobacter pylori in Finland. Int J Antimicrob Agents. 2011;37(1):22-5

38. Ang TL, Fock KM, Ang D, Kwek AB, Teo EK, Dhamodaran S. The changing profile of helicobacter pylori antibiotic resistance in Singapore: a 15-year study. Helicobacter. 2016;21(4):261-5.

39. Kim JJ, Reddy R, Lee M, Kim JG, El-Zaatari FA, Osato MS, et al. Analysis of metronidazole, clarithromycin and tetracycline resistance of helicobacter pylori isolates from Korea. J Antimicrob Chemother. 2001; 47(4):459-61.

40. Hwang TJ, Kim N, Kim HB, Lee BH, Nam RH, Park JH, et al. Change in antibiotic resistance of helicobacter pylori strains and the effect of A2143G point mutation of $23 \mathrm{~S}$ rRNA on the eradication of $\mathrm{H}$. pylori in a single center of Korea. J Clin Gastroenterol. 2010;44(8):536-43.

41. Boyanova L, llieva J, Gergova G, Davidkov L, Spassova Z, Kamburov V, et al. Numerous risk factors for helicobacter pylori antibiotic resistance revealed by extended anamnesis: a Bulgarian study. J Med Microbiol. 2012;61(Pt 1): 85-93.

42. Jing JJ, Liu HY, Hao JK, Wang LN, Wang YP, Sun LH, et al. Gastric cancer incidence and mortality in Zhuanghe, China, between 2005 and 2010. World J Gastroenterol. 2012;18(11):1262-9.

43. Broutet N, Tchamgoue S, Pereira E, Lamouliatte H, Salamon R, Megraud F. Risk factors for failure of helicobacter pylori therapy--results of an individual data analysis of 2751 patients. Aliment Pharmacol Ther. 2003;17(1):99-109. 
44. Miftahussurur M, Syam AF, Nusi IA, Makmun D, Waskito LA, Zein LH, et al. Surveillance of helicobacter pylori antibiotic susceptibility in Indonesia: different resistance types among regions and with novel genetic mutations. PLoS One. 2016;11(12):e0166199.

45. Lim JH, Lee DH, Lee ST, Kim N, Park YS, Shin CM, et al. Moxifloxacincontaining triple therapy after non-bismuth quadruple therapy failure for helicobacter pylori infection. World J Gastroenterol. 2015;21(46):13124-31.

46. Hirata Y, Serizawa T, Shichijo S, Suzuki N, Sakitani K, Hayakawa Y, et al. Efficacy of triple therapy with esomeprazole, amoxicillin, and sitafloxacin as a third-line helicobacter pylori eradication regimen. Int J Infect Dis. 2016;51:66-9.

47. An B, Moon BS, Kim H, Lim HC, Lee YC, Lee G, et al. Antibiotic resistance in helicobacter pylori strains and its effect on $\mathrm{H}$. pylori eradication rates in a single center in Korea. Ann Lab Med. 2013;33(6):415-9.

48. Uotani T, Miftahussurur M, Yamaoka Y. Effect of bacterial and host factors on helicobacter pylori eradication therapy. Expert Opin Ther Targets. 2015; 19(12):1637-50.

49. Van Doorn LJ, Schneeberger PM, Nouhan N, Plaisier AP, Quint WGV, De Boer WA. Importance of helicobacter pylori cagA and vacA status for the efficacy of antibiotic treatment. Gut. 2000;46(3):321-6.

50. Niu SL, Yang F. Relationship between lansoprasoi triple therapy effect and alleles of vacuolating cytotoxin genotype in patients with gastric ulcer. Chin J Pract Med. 2014;(41):02.

51. Scholte GH, van Doorn LJ, Cats A, Bloemena E, Lindeman J, Quint WG, et al. Genotyping of helicobacter pylori in paraffin-embedded gastric biopsy specimens: relation to histological parameters and effects on therapy. Am J Gastroenterol. 2002;97(7):1687-95.

52. Russo F, Berloco P, Cuomo R, Caruso ML, Di Matteo G, Giorgio P, et al. Helicobacter pylori strains and histologically-related lesions affect the outcome of triple eradication therapy: a study from southern Italy. Aliment Pharmacol Ther. 2003;17(3):421-8

53. Kang D, Gong Y, Zhu Y, Li A, Dong N, Piao Y, et al. The biological activity of H. pylori SlyD in vitro. Helicobacter. 2013;18(5):347-55.

\section{Publisher's Note}

Springer Nature remains neutral with regard to jurisdictional claims in published maps and institutional affiliations.

Ready to submit your research? Choose BMC and benefit from:

- fast, convenient online submission

- thorough peer review by experienced researchers in your field

- rapid publication on acceptance

- support for research data, including large and complex data types

- gold Open Access which fosters wider collaboration and increased citations

- maximum visibility for your research: over $100 \mathrm{M}$ website views per year

At $\mathrm{BMC}$, research is always in progress.

Learn more biomedcentral.com/submissions 